\title{
Evaluation of Level of TNF- $\alpha$ In Chronic Periodontitis Patients with Gestational Diabetes Mellitus after Phase I Periodontal Therapy
}

\author{
Omneya M Elkadi ${ }^{1 *}$, Gihane Gharib Madkour ${ }^{2}$, Hala Salem Elmenoufy ${ }^{3}$ and Mahmoud El Refai ${ }^{4}$ \\ ${ }^{1}$ Misr University for Science and Technology, Egypt \\ ${ }^{2}$ Department of Oral Diagnosis Oral Medicine and Periodontology, Cairo University, Egypt
}

${ }^{3}$ Department of Oral Medicine and Periodontology, Misr University for Science and Technology, Egypt

${ }^{4}$ Department of Oral Diagnosis Oral Medicine and Periodontology, Cairo University, Egypt

Submission: May 21, 2018; Published: June 11, 2018

*Corresponding author: Omneya M Elkadi, Misr University for Science and Technology, Egypt, Email: ninielkadi@gmail.com

\begin{abstract}
Background: There is little number of studies that address the inter-relationship of Gestational Diabetes Mellitus (GDM) and periodontitis during pregnancy. Hence, this study was conducted to provide further evidence in the possible association between chronic periodontitis and GDM by evaluating the level of Tumor necrosis factor-alpha (TNF- $\alpha$ ) of chronic periodontitis patients with GDM after phase I periodontal therapy.

Subjects and methods: This study was conducted on 40 subjects divided into 2 groups: 20 pregnant females suffering from gestational diabetes mellitus associated with moderate to severe chronic periodontitis and 20 systemically free pregnant females suffering from moderate to severe chronic periodontitis. The periodontal status of the subjects was assessed at baseline before phase I periodontal therapy and 2 months after completion of the treatment: All subjects have been screened by comprehensive periodontal examination and full periodontal charts were obtained. The following clinical parameters were assessed to determine the clinical periodontal status of patients: Plaque Index (PI), Gingival Index (GI), Probing Pocket Depth (PPD), and Clinical Attachment Level (CAL). Gingival Crevicular Fluid (GCF) and serum samples were collected from both study groups to detect TNF- $\alpha$ level. Regarding the assessment of TNF- $\alpha$, Real-time reverse-transcriptase Polymerase Chain Reaction (RT) PCR technique was used.
\end{abstract}

Results: Results of the present study observed statistically significant reduction in TNF- $\alpha$ level after 2 months from phase I periodontal therapy. The current study showed that, there was a statistically significant positive (direct) correlation between TNF- $\alpha$ level, PI, GI, PPD and CAL measurement at baseline and after 2 months from phase I periodontal therapy.

Conclusion: It is shown that the levels of TNF- $\alpha$ in GCF and serum before treatment were higher in GDM group (group 1) than in the control group. Thus, the examination of TNF- $\alpha$ may enhance the understanding of pathogenesis of periodontitis and GDM and its assessment in the treatment process may result in better control of the disease.

Keywords: Chronic Periodontitis; GDM; TNF- $\alpha$

\section{Introduction}

Periodontal diseases are a group of oral inflammatory diseases that are influenced by host response factors. In the last decades, there was a consensus toward the [1-3] converse relationship between periodontal disease and systemic disease. Evidence suggest that periodontal disease is an independent riskfactor for a number of significant systemic diseases so much so that they have brought a shift in the rationale about causality and the directionality of oral and systemic [4,5] associations. This shift is encapsulated by the new term periodontal medicine.

Cytokines (Greek "cyto-", cell; and "-kinos", movement) are a family of signaling molecules that mediate and regulate immunity, inflammation, hematopoiesis, and many other cellular processes. TNF- $\alpha$ is considered as one of the adipokines which are group of over 600 bioactive molecules produced by adipose tissue that $[6,7]$ acts as paracrine and endocrine hormones.

When adipose tissue inflammation and dysfunction are established, adipokine secretion is significantly changed toward a diabetogenic, proinflammatory and atherogenic pattern. TNF- $\alpha$ is a pro-inflammatory cytokine that plays a central role in inflammatory reaction, alveolar bone resorption, and the loss of connective tissue attachment. It is positively correlated with Matrix metalloproteinases (MMPs), Prostaglandin E2 (PGE2) and nuclear factor kappa [8-10] ligand (RANKL) expression. 
Gingival Crevicular Fluid (GCF) is an inflammatory exudate that seeps into gingival crevices or periodontal pockets around teeth with inflamed gingiva. It can be collected from healthy gingival sulcus, although only in small amount. GCF represents the transudate of gingival tissue interstitial fluid produced by an osmotic gradient in the healthy periodontium. It contains different substances including: immunoglobulin, microorganisms, toxins, cells, and lysosomal enzymes and markers. GCF is regarded as a window for non-invasive analysis of periodontal [11-14] conditions, including markers of connective tissue and bone destruction.

Evaluation of the molecular markers of tissue destruction in serum was sought to clarify the possible interactions between periodontitis and various systemic diseases and conditions such as gestational diabetes mellitus GDM and adverse pregnancy outcomes). Serum provides information about the inflammatory stimulus and the response generated in circulation towards the periodontal $[15,16]$ pathogens that colonize the sub-gingival area.

The present study was conducted to evaluate the levels of TNF- $\alpha$ in GCF and serum in chronic periodontitis patients with or without GDM before and after phase I (non-surgical) periodontal therapy and its correlation to periodontal clinical parameters.

\section{Aims of the Study}

The aim of the present study was to evaluate the possible effect of phase I (non-surgical) periodontal therapy on TNF- $\alpha$ in chronic periodontitis patient with GDM.

\section{Subjects, Materials and Methods}

\section{Study Population}

Forty adult pregnant female subjects selected from the obstetrics \& gynecology department, Faculty of Medicine, Cairo University \& the obstetrics \& gynecology department, Faculty of Medicine, Misr University for Science \& Technology and El Galaa Maternity Hospital. Participants were pregnant females aged between 20-40 years, at the second trimester of pregnancy, not taking any local or systemic medications \& had no periodontal therapy for the previous six months and were not using any mouth wash. Exclusion criteria were: Already diabetic participants, over 40 years of age, smokers, and participants having known systemic disease other than cases of GDM group (group 1) and participants who had periodontal therapy at the last 6 months.

\section{Cases and Controls}

The present study was conducted on 40 subjects divided into 2 groups of 20 subjects each: Group (1); Included 20 pregnant females suffering from GDM associated with moderate to severe chronic periodontitis. Group (2); Included 20 systemically free pregnant females suffering from moderate to severe chronic periodontitis acting as control group. All pregnant females included in this study had a moderate to severe chronic periodontitis and had been free from any systemic disease according to Cornell medical index except GDM cases in GDM group (group 1). All pregnant women have undergone a laboratory screening test for GDM consisting of fasting blood glucose test (no caloric intake for 8 hours) and [17] 2 hours post-prandial glucose test.

\section{Assessment of periodontal condition}

All participants were screened by comprehensive periodontal examination and full periodontal charts were obtained. The following clinical parameters were assessed to determine the [1820] clinical periodontal status of patients: PI, GI, PD, and CAL.

\section{The study design}

The periodontal status of the participants was assessed at baseline before phase I periodontal therapy and 2 months after completion of the treatment. All participants received phase I periodontal therapy that includes oral hygiene instructions, scaling and root planning under local anesthesia using sharp scalers, Gracey curettes and ultrasonic debridement.

\section{Samples collection}

GCF samples were collected from the selected sites for assessment of TNF- $\alpha$ level at baseline before initial periodontal therapy and 2 months after the completion of Phase I therapy. The GCF samples were collected using filter paper strips $(2 \mathrm{~mm}$ $\mathrm{x} 8 \mathrm{~mm}$ ). $5 \mathrm{ml}$ of blood was collected from the antecubital fossa by venipuncture using 20 gauge needle and $2 \mathrm{ml}$ syringes and immediately transferred to the laboratory. Samples were allowed to clot for 1 hour at room temperature centrifuged for 10 minutes $\left(4^{\circ} \mathrm{C}\right)$ and serum was extracted. Collected GCF and serum samples were stored at $-40^{\circ} \mathrm{C}$ before used for assay procedure. Assessment of TNF- $\alpha$ in GCF and serum by PCR Serum and GCF samples were assayed for TNF- $\alpha$ levels by PCR using Qiagen extraction kit (Qiagen, Valencia, CA, and USA) Serum and GCF samples were taken before the phase I periodontal therapy and 2 months after the completion of active therapy (debridement).

\section{Statistical Analysis}

Values of clinical parameters and TNF- $\alpha$ level were presented as Mean and Standard Deviation (SD) values. Data were explored for normality using Kolmogorov Smirnov test of normality. The results of Kolmogorov-Smirnov test indicated that most of data were normally distributed (parametric data), so parametric tests were used for the comparisons.

\section{Results}

\section{Scores ofTNF- $\alpha$ (GCF) and significance of the difference before and after treatment (paired t test) and between groups (unpaired t test)}

A higher mean score was recorded in GDM group (group 1). Unpaired t test revealed that this difference was statistically significant preoperatively $(\mathrm{p}<0.0001)$, but insignificant post operatively $(\mathrm{P}=0.0534)$. Treatment decreased the TNF- $\alpha$ (GCF) level in each group. Paired $t$ test revealed that this decrease was statistically significant in GDM group (group 1) $(\mathrm{P}<0.0001)$, but insignificant in control group ( $\mathrm{p}=0.3200)$. Comparing the percent 
decrease in both groups, unpaired t test revealed a greater significant decrease in GDM group (group 1) $(\mathrm{p}<0.0001)$ as shown in (Table 1).

Table 1: Scores of TNF- $\alpha$ (GCF) and significance of the difference before and after treatment (paired $t$ test) and between groups (unpaired $\mathrm{t}$ test).

\begin{tabular}{|c|c|c|c|c|c|}
\hline & \multicolumn{4}{|c|}{ Score } \\
\hline & & Group 1 & Control & $\begin{array}{c}\text { T Value } \\
\text { (unpaired } \\
\text { T test) }\end{array}$ & $\begin{array}{c}\text { P Value } \\
\text { (unpaired } \\
\text { T test) }\end{array}$ \\
\hline \multirow{4}{*}{$\begin{array}{l}\text { TNF- } \alpha \\
\text { (GCF) } \\
\text { before }\end{array}$} & Mean & 2.8 & 1.29 & \multirow{4}{*}{13.08} & \multirow{4}{*}{$<0.0001^{*}$} \\
\hline & SD & 0.42 & 0.3 & & \\
\hline & Min & 2.13 & 0.96 & & \\
\hline & Max & 3.43 & 1.67 & & \\
\hline \multirow{4}{*}{$\begin{array}{c}\text { TNF- } \alpha \\
\text { (GCF)- } \\
\text { post } \\
\text { therapy }\end{array}$} & Mean & 1.41 & 1.17 & \multirow{4}{*}{1.994} & \multirow{4}{*}{ ns 0.0534} \\
\hline & SD & 0.31 & 0.44 & & \\
\hline & Min & 0.96 & 0.82 & & \\
\hline & Max & 1.8 & 1.73 & & \\
\hline \multicolumn{2}{|c|}{$\begin{array}{l}\mathrm{T} \text { value (paired } \mathrm{t} \\
\text { test) }\end{array}$} & 11.9 & 1.0077 & \multirow{2}{*}{\multicolumn{2}{|c|}{------ }} \\
\hline \multicolumn{2}{|c|}{$\begin{array}{l}\mathrm{P} \text { value (paired } \mathrm{t} \\
\text { test) }\end{array}$} & $<0.0001^{*}$ & $0.3200 \mathrm{~ns}$ & & \\
\hline
\end{tabular}

*significant ns=non-significant

\section{Scores of TNF- $\alpha$ (serum) and significance of the difference before and after treatment (paired $t$ test) and between groups (unpaired $t$ test)}

Table 2: Scores of TNF- $\alpha$ (Serum) and significance of the difference before and after treatment (paired t test) and between groups (unpaired $\mathrm{t}$ test).

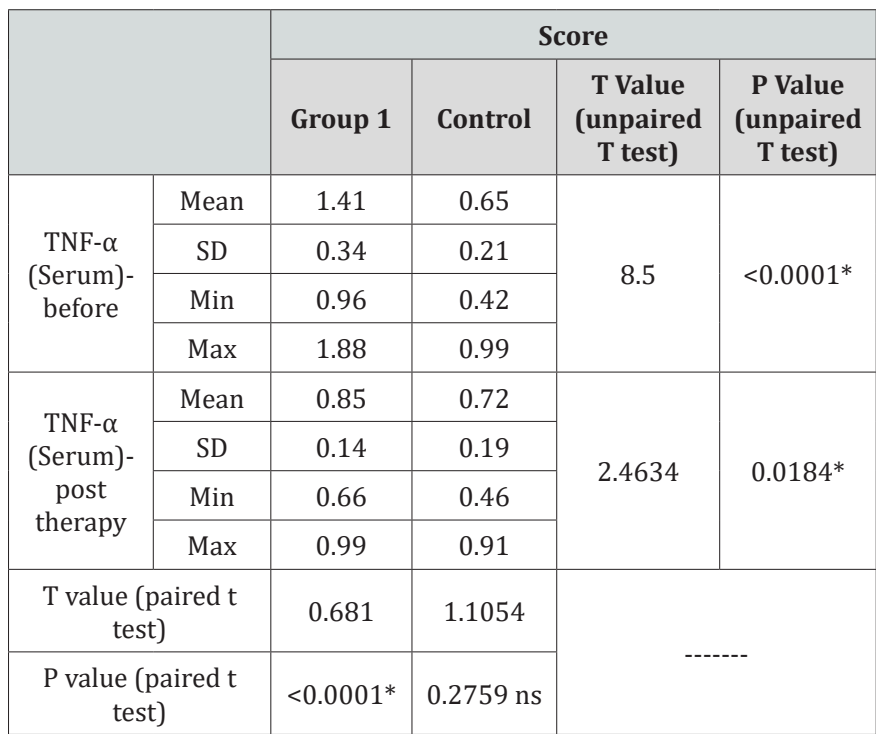

*significant ns=non-significant at $p>0.05$

A higher mean score was recorded in GDM group (group 1). Unpaired t test revealed that this difference was statistically significant preoperatively $(\mathrm{p}<0.0001)$ and post operatively $(\mathrm{P}=0.0184)$. Treatment decreased the TNF- $\alpha$ (serum) level in GDM group (group 1) only. Paired t test revealed that this decrease was statistically significant in GDM group (group 1) $(\mathrm{P}<0.0001)$, while the increase in control group was insignificant $(p=0.2759)$. Comparing the percent change in both groups, unpaired t test revealed a greater significant decrease in GDM group (group 1) $(\mathrm{p}<0.0001)$ as shown in (Table 2-6).

Table 3: Correlation between TNF- $\alpha$ and Plaque index (Pearson correlation test).

\begin{tabular}{|c|c|c|c|}
\hline Correlation of TNF- $\boldsymbol{\alpha}$ (GCF) & $\mathbf{R}$ & $\mathbf{R}^{\mathbf{2}}$ & Significance \\
\hline 1- PI (group1) & 0.9117 & 0.8312 & Strong positive \\
\hline 2- PI (control) & 0.3509 & 0.1231 & Weak positive \\
\hline
\end{tabular}

Table 4: Correlation between TNF- $\alpha$ and gingival index (Pearson correlation test).

\begin{tabular}{|c|c|c|c|}
\hline Correlation of TNF- $\boldsymbol{\alpha}$ (GCF) & $\mathbf{R}$ & $\mathbf{R}^{2}$ & Significance \\
\hline 1- PI (group1) & 0.8427 & 0.7101 & Strong positive \\
\hline 2- PI (control) & 0.313 & 0.0908 & Weak positive \\
\hline
\end{tabular}

Table 5: Correlation between TNF- $\alpha$ and PPD (Pearson correlation test).

\begin{tabular}{|c|c|c|c|}
\hline Correlation of TNF- $\alpha$ (GCF) & $\mathbf{R}$ & $\mathbf{R}^{2}$ & Significance \\
\hline 1- PI (group1) & 0.7449 & 0.5549 & Moderate positive \\
\hline 2- PI (control) & -0.0246 & 0.0006 & Weak negative \\
\hline
\end{tabular}

Table 6: Correlation between TNF- $\alpha$ and CAL (Pearson correlation test)

\begin{tabular}{|c|c|c|c|}
\hline Correlation of TNF- $\alpha$ (GCF) & $\mathbf{R}$ & $\mathbf{R}^{2}$ & Significance \\
\hline 1- PI (group1) & 0.8427 & 0.7101 & Strong positive \\
\hline 2- PI (control) & 0.313 & 0.0908 & Weak positive \\
\hline
\end{tabular}

\section{Discussion}

Studies have shown that there are elevated inflammatory cytokines in patients with GDM and diabetes. Diabetes and periodontal inflammation clearly interact, with overt diabetes associated with an increased risk of more severe periodontitis while periodontitis has been associated with worsened glycemic control in [21-30] subjects with diabetes. Consequently, the present study was conducted to evaluate the levels of TNF- $\alpha$ in GCF and serum in chronic periodontitis patients with or without gestational diabetes mellitus GDM before \& after phase I (nonsurgical) periodontal therapy and its correlation to periodontal clinical [31] parameters.

Participants over 40 years of age were excluded from this study due to the effect of estrogen level decrease upon TNF- $\alpha$. Moreover, smokers were excluded from this study as it was found that tissues exposed to tobacco carcinogens respond by expressing elevated levels of cytokines in those tissues presumably as a part of [32-35] injury response mechanism.

GCF provides an accurate representation of tissue and serum concentrations of inflammatory mediators. Evaluation of the molecular markers of tissue destruction in serum was sought to clarify the possible interactions between periodontitis and various systemic diseases and conditions such as GDM and [3639] adverse pregnancy outcomes. 


\section{Advances in Dentistry \& Oral Health}

The suitability of TNF- $\alpha$ in GCF as a possible indicator of periodontal disease was first assessed by Rossomando 40. TNF- $\alpha$ is a pro-inflammatory cytokine that is often over expressed in periodontitis and is responsible for alveolar bone resorption during periodontitis. Moreover, TNF- $\alpha$ has been reported to be an $[41,42]$ insulin antagonist.

The evidence that insulin resistance is linked to TNF- $\alpha$ is well established. Additionally, TNF- $\alpha$ has been demonstrated to be the most significant predictor of pregnancy-induced insulin resistance and be more highly synthesized and released from the placenta compared with IL- 6 or IL- 843,44 . Therefore, TNF- $\alpha$ was the inflammatory marker of choice to be used to evaluate the inflammatory status in patients with GDM.

Real-time reverse-transcriptase Polymerase Chain Reaction (RT) PCR gene expression method was chosen as it quantitates the initial amount of the template most specifically, sensitively and reproducibly, and is a preferable alternative to other forms of quantitative RT-PCR that detect the amount of final [45-47] amplified product at the end-point.

In the present study it was observed that the gestational diabetes mellitus GDM group had a higher mean TNF- $\alpha$ level when compared to the control group at baseline before initial periodontal therapy and 2 months after the completion of Phase therapy which supports the hypothesis of an association between [48-50] periodontal disease and gestational diabetes mellitus GDM .Hence, we can conclude that the local inflammatory changes that have resulted in elevated levels of TNF- $\alpha$ in GCF might have contributed to the increased levels of TNF- $\alpha$ in serum i.e., systemic "Spill" of cytokine via the circulation as reported by Offenbacher [51].

Goktas et al. [52] concluded that obesity is a chronic lowgrade inflammatory disease characterized by overproduction of inflammatory adipokines by adipose tissue and this may be the link between obesity, Cardiovascular diseases (CVD) and diabetes. One of these adipokines is Tumor Necrosis Factor Alpha (TNF- $\alpha$ ) [53-56] contributing to the pathogenesis of metabolic syndrome, insulin resistance, type 2 diabetes, and cardiovascular disease. Gestational diabetes mellitus GDM has been considered a great risk for developing more severe periodontal disease. It is important to clarify that gestational diabetes mellitus GDM does not exclude the possibility that unrecognized glucose intolerance may be present prior to [57-61] pregnancy. Therefore, a probable undiagnosed case of hyperglycemia could be responsible for the increased level of periodontal disease in our GDM group (group 1).

The observed association between periodontal disease and gestational diabetes mellitus GDM might be explained by gestational diabetes mellitus GDM causing periodontitis, similar to type 1 or 2 diabetes where long duration of elevated blood glucose levels (hyperglycemia), impaired insulin resistance, vascular changes, altered oral microflora, abnormal collagen metabolism, and the consequent hyperglycemia and hyperlipidemia of diabetes result in metabolic alterations which then exacerbate the bacteriainduced inflammatory [62] periodontitis.

However, compared to type 1 or 2 diabetes, gestational diabetes mellitus GDM only represents an early stage of glucose dysregulation and a temporary impaired glucose tolerance that occur in later pregnancy. The elevated glucose levels in the majority of women diagnosed with gestational diabetes mellitus GDM will usually [63] return to normal after birth. Therefore, the hyperglycemia of gestational diabetes mellitus GDM may be too mild and of too short duration to have a significant effect on gingival tissues and to cause a destruction of the supporting structures of the teeth manifested as periodontitis.

An alternative explanation is that periodontal disease may be a cause, instead of the result of gestational diabetes mellitus GDM. Periodontal infection, a local and chronic sub-clinical inflammation, triggers a maternal systemic inflammatory response. Since pregnancy itself is a stressful state with increased inflammatory activity and marked insulin resistance, such an infection-induced insulin resistance in response to maternal periodontal infection may thus worsen the preexisting pregnancy-induced insulin resistance that may cause impaired glucose tolerance [64] and the manifestation of gestational diabetes mellitus GDM.

There may be a common genetic cause for both periodontal disease and gestational diabetes mellitus GDM that results in the observed association between the two disorders. Although there is lack of clear correlation between the gene polymorphisms and GDM, a few studies suggested that cytokines such as TNF- $\alpha$, IL6 , and IL-1 polymorphisms may be associated with the risk of insulin [65-67] resistance or type 2 diabetes as well as periodontal disease.

Therefore, there is a possibility that pre-existing genetic polymorphisms result in imbalances between the pro vs. antiinflammatory cytokine systems predisposing to both periodontal disease and gestational diabetes mellitus GDM simultaneously. However, the results of the study conducted by Mishra et al. [68] showed that periodontal disease is not significantly associated with gestational diabetes mellitus GDM.

In this study, the systemic reduction of TNF- $\alpha$ level was positively correlated with reduction of Plaque Index (PI), Gingival Index (GI), Probing Pocket Depth (PPD), and Clinical Attachment Level (CAL) that are important inflammatory indices of periodontitis, which might be part of the proof of the mechanism that links the focal infection with systemic cytokine levels.

ZHOU et al. [69] reported that the systemic reduction of TNF- $\alpha$ level was positively correlated with reduction of Bleeding Index (BI) and Plaque Index (PI), indicating that local periodontal treatment could reduce the systemic cytokines level in chronic periodontitis subjects with chronic heart disease. The possible mechanisms that connect focal infection in periodontitis with systemic cytokine levels might be that the TNF- $\alpha$ stimulated the 


\section{Advances in Dentistry \& Oral Health}

expression of interleukin 6 (IL-6), which consequently augmented the $\mathrm{C}$-reactive protein (CRP) gene expression in $[70,71]$ the liver.

Finally, we can conclude that the Improvement of periodontal condition is found to be associated with reduction in TNF- $\alpha$ levels and that phase 1 periodontal therapy for gestational diabetic females is a safe \& effective line of treatment. More research on the biological effects of TNF- $\alpha$ should be considered and further studies are needed to understand the role of TNF- $\alpha$ in periodontal health and disease.

\section{References}

1. Pihlstrom BL, Michalowicz BS, Johnson NW (2005) Periodontal diseases. The Lancet 366(9499): 1809-1820.

2. James E Ferguson II, Hansen WF, Novak KF, Novak MJ (2007) Should we treat periodontal disease during gestation to improve pregnancy outcomes? Clinical obstetrics and gynecology 50(2): 454-467.

3. Dumitrescu A, Inagaki K (2010) Interrelationship between periodontal disease and mortality in CVD, metabolic syndrome \& diabetes mellitus. In: Etiology and Pathogenesis of periodontal diseases. Verlag, Berlin Heidelberg, Springer, New York, USA, pp. 125-157.

4. Garcia RI, Henshaw MM, Krall EA (2001) Relationship between periodontal disease and systemic health. Periodontology 2000 25(1): 21-36.

5. Erdemir EO, Nalcaci R, Caglayan O (2008) Evaluation of systemic markers related to anemia of chronic disease in the peripheral blood of smokers and non-smokers with chronic periodontitis. Eur J Dent 2(2): 102-109.

6. Feldmann M (2008) Many cytokines are very useful therapeutic targets in disease. J Clin Invest 118(11): 3533-3536

7. Blüher M (2014) Adipokines-removing road blocks to obesity and diabetes therapy. Mol Metab 3(3): 230-240

8. Graves D (2008) Cytokines that promote periodontal tissue destruction Journal of periodontology 79(8 Suppl): 1585-1591.

9. Blüher M (2009) Adipose tissue dysfunction in obesity. Exp Clin Endocrinol Diabetes 117(6): 241-250.

10. Blüher M (2014) Adipokines-removing road blocks to obesity and diabetes therapy. Molecular metabolism 3(3): 230-240.

11. Alfano MC (1974) The origin of gingival fluid. Journal of theoretical biology 47(1): 127-136.

12. Armitage GC (2004) Analysis of gingival crevice fluid and risk of progression of periodontitis. Periodontology 2000 34(1): 109-119.

13. Uitto VJ (2003) Gingival crevice fluid-an introduction. Periodontology 2000 31(1): 9-11

14. AlRowis R, AlMoharib HS, AlMubarak A, Bhaskardoss J, Preethanath RS, et al. (2014) Oral fluid-based biomarkers in periodontal disease-Part 2. Gingival crevicular fluid. Journal of international oral health: $\mathrm{JIOH}$ 6(5): $126-35$

15. Pussinen PJ, Paju S, Mantyla P, Sorsa T (2007) Serum microbial-and host-derived markers of periodontal diseases: a review. Current medicinal chemistry 14(22): 2402-2412.

16. Buduneli N, Kinane DF (2011) Host-derived diagnostic markers related to soft tissue destruction and bone degradation in periodontitis Journal of clinical periodontology 38(supp 1): 85-105.

17. Armitage GC (1999) Development of a classification system for periodontal diseases and conditions. Annals of periodontology 4(1): $1-6$.
18. Loe H, Silness J (1963) Periodontal diseases in pregnancy.1.Correlation between oral hygiene and periodontal condition. Acta Odontol Scand 21: 121-135.

19. Silness J, Löe H (1964) Periodontal disease in pregnancy II. Correlation between oral hygiene and periodontal condition. Acta odontologica scandinavica 22(1): 121-135.

20. Armitage GC (1999) Development of a classification system for periodontal diseases and conditions. Annals of periodontology 4(1): $1-6$.

21. Pradhan AD, Manson JE, Rifai N, Buring JE, Ridker PM (2001) C-reactive protein, interleukin 6 , and risk of developing type 2 diabetes mellitus Jama 286(3): 327-334.

22. Coughlan MT, Oliva K, Georgiou HM, Permezel JMH, Rice GE (2001) Glucose-induced release of tumour necrosis factor-alpha from human placental and adipose tissues in gestational diabetes mellitus. Diabetic Medicine 18(11): 921-927.

23. Cseh K, Baranyi E, Melczer Z, Csakany GM, Speer G, et al. (2002) The pathophysiological influence of leptin and the tumor necrosis factor system on maternal insulin resistance: negative correlation with anthropometric parameters of neonates in gestational diabetes. Gynecological endocrinology 16(6): 453-460.

24. Kirwan JP, Hauguel-De Mouzon S, Lepercq J, Challier JC, Huston-Presley $\mathrm{L}$, et al. (2002) TNF- $\alpha$ is a predictor of insulin resistance in human pregnancy. Diabetes 51(7): 2207-2213.

25. Di Benedetto A, Russo GT, Corrado F, Di Cesare E, Alessi E, et al. (2005) Inflammatory markers in women with a recent history of gestational diabetes mellitus. Journal of endocrinological investigation 28(3): 3438.

26. Bascones-Martinez A, Matesanz-Perez P, EscribanoBermejo M González-Moles MÁ, Bascones-Ilundain J, et al. (2011) Periodontal disease and diabetes-Review of the Literature. Med Oral Patol Oral Cir Bucal 16(6): e722-e729.

27. Bascones-Martinez A, Gonzalez-Febles J, SanzEsporrin J (2014) Diabetes and peri- odontal disease. Review of the literature. Amer- ican Journal of Dentistry 27(2): 63-67.

28. Lakschevitz F, Aboodi G, Tenenbaum H, Glogauer M (2011) Diabetes and periodontal diseases: interplay and links. Current Diabetes Review 7(6): 433-439.

29. Negrato CA, Tarzia O, Jovanovic L, Chinellato LE (2013) Periodontal disease and diabetes mellitus. Journal of Applied Oral Science 21(1): $1-12$.

30. Sima C, Glogauer M (2013) Diabetes mellitus and periodontal diseases. Current Diabetes Reports 13(3): 445-452.

31. Sharma P, Singh N, Singh V, Singh S, vardhan Singh H, at al. (2006) Tumor necrosis factor alpha (TNF- $\alpha$ ) and estrogen hormone in osteoarthritic female patients. Indian Journal of Clinical Biochemistry 21(1): 205-207.

32. Lopez NJ, Socransky SS, Da Silva I, Japlit MR, Haffajee AD (2006) Effects of metronidazole plus amoxicillin as the only therapy on the microbiological and clinical parameters of untreated chronic periodontitis. J Clin Periodontol 33(9): 648-660.

33. Rhodus NL, Cheng B, Bowles W, Myers S, Miller L, et al. (2006) Proinflammatory cytokine levels in saliva before and after treatment of (erosive) oral lichen planus with dexamethasone. Oral diseases 12(2): 112-116.

34. Napimoga MH, Nunes LHAC, Maciel AAB, Demasi APD, Benatti BB, et al. (2011) Possible Involvement of IL-21 and IL-10 on Salivary IgA Levels in Chronic Periodontitis Subjects. Scandinavian journal of immunology 74(6): 596-602. 


\section{Advances in Dentistry \& Oral Health}

35. Giannobile W V (1997) Crevicular fluid biomarkers of oral bone loss. Curr. Opin. Periodontol 4: 11-20.

36. Champagne CM, Buchanan W, Reddy MS, Preisser JS, Beck JD, et al. (2003) Potential for gingival crevice fluid measures as predictors of risk for periodontal diseases. Periodontology 2000 31(1): 167-180.

37. Armitage GC (2004) Analysis of gingival crevice fluid and risk of progression of periodontitis. Periodontology 2000 34(1): 109-119.

38. Buduneli N, Kinane DF (2011) Host-derived diagnostic markers related to soft tissue destruction and bone degradation in periodontitis. Journal of clinical periodontology 38(Suppl 11): 85-105.

39. Pussinen PJ, Paju S, Mantyla P, Sorsa T (2007) Serum microbial-and host-derived markers of periodontal diseases: a review. Current medicinal chemistry 14(22): 2402-2412.

40. Rossomando EF, Kennedy JE, Hadjimichael J (1990) Tumour necrosis factor alpha in gingival crevicular fluid as a possible indicator of periodontal disease in humans. Archives of Oral Biology 35(6): 431434

41. Kumari M, Naik SB, NamitaShanbhag (2011) Diabetes and peridontitis, Acasual link or a two way street? AOSR 1(4): 221-227.

42. Stashenko P, Van Dyke T, Tully P, Kent JrR, Sonis S, et al. (2011) Inflammation and genetic risk indicators for early periodontitis in adults. Journal of periodontology 82(4): 588-596.

43. Lappas M, Permezel M, Rice GE (2004) Release of proinflammatory cytokines and 8-isoprostane from placenta, adipose tissue, and skeleta muscle from normal pregnant women and women with gestational diabetes mellitus. The Journal of Clinical Endocrinology \& Metabolism 89(11): 5627-5633.

44. Xu J, Zhao YH, Chen YP, Yuan XL, Wang J, et al. (2014) Maternal circulating concentrations of tumor necrosis factoralpha, leptin, and adiponectin in gestational diabetes mellitus: a systematic review and meta-analysis. The Scientific World Journal 2014: 926932.

45. Freeman WM, Walker SJ, Vrana KE (1999) Quantitative RTPCR: pitfalls and potential. Biotechniques 26(1): 112-125.

46. Raeymaekers L (2000) Basic principles of quantitative PCR. Molecular biotechnology 15(2): 115-122.

47. Espy MJ, Uhl JR, Sloan LM, Buckwalter SP, Jones MF, et al. (2006) Realtime PCR in clinical microbiology: applications for routine laboratory testing. Clinical microbiology reviews 19(1): 165-256.

48. Xiong X, Buekens P, Fraser WD, Beck J, Offenbacher S (2006) Periodontal disease and adverse pregnancy outcomes: a systematic review. BJOG: An International Journal of Obstetrics \& Gynaecology 113(2): 135-143.

49. Novak KF, Taylor GW, Dawson DR, II JEF, Novak MJ (2006) Periodontitis and gestational diabetes mellitus: exploring the link in NHANES III. Journal of public health dentistry 66(3): 163-168.

50. Dasanayake AP, Chhun N, Tanner ACR, Craig RG, Lee MJ, et al. (2008) Periodontal pathogens and gestational diabetes mellitus. Journal of dental research 87(4): 328-333.

51. Offenbacher S (1996) Periodontal diseases: pathogenesis. Annals of periodontology 1(1): 821-878.

52. Goktas Z, Moustaid-Moussa N, Shen CL, Boylan M, Mo H, et al. (2013) Effects of bariatric surgery on adipokine-induced References106 inflammation and insulin resistance. Front Endocrinol (Lausanne) 4 69.

53. Ohman MK, Shen Y, Obimba CI, Wright AP, Warnock M, et al. (2008) Visceral adipose tissue inflammationaccelerates atherosclerosis in apolipoprotein E-defcient mice. Circulation 117(6): 798-805.
54. Van de Voorde J, Pauwels B, Boydens C, Decaluwé K (2013) Adipocytokines in relation to cardiovascular disease. Metabol 62(11): 1513-1521.

55. Blüher M (2014) Adipokines-removing road blocks to obesity and diabetes therapy. Molecular metabolism 3(3): 230-240.

56. Fisman EZ, Tenenbaum A (2014) Adiponectin: a manifold therapeutic target for metabolic syndrome, diabetes, and coronary disease? Cardiovasc. Diabetol 13: 103

57. Metzger BE, Buchanan TA, Coustan DR, de Leiva A, Dunger DB, et al 2007. Summary and recommendations of the Fifth International Workshop Conference on Gestational Diabetes Mellitus. Diabetes Care 30(Suppl 2): S251-S260.

58. Dasanayake AP, Chhun N, Tanner ACR, Craig RG, Lee MJ, et al. (2008) Periodontal pathogens and gestational diabetes mellitus. Journal of dental research 87(4): 328-333.

59. Kasaj A, Zafropoulos GG, Tekyatan H, Pistorius A, Willershausen B (2008) Periodontal disease status of pregnant women with diabetes mellitus. Coll Antropol 32(1): 115-118.

60. Xiong X, Elkind-Hirsch KE, Vastardis S, Delarosa RL, Pridjian G, et al. (2009) Periodontal disease is associated with gestational diabetes mellitus: a case-control study. Journal of periodontology 80(11): 17421749.

61. Bagis N, Bostanci HS (2013) The Relationship between Gestational Diabetes Mellitus and Periodontal Health: A Case-Control Study. International Journal of Experimental Dental Science 2(2): 71.

62. Matthews DC (2002) The relationship between diabetes and periodontal disease. Journal-Canadian Dental Assossiation 68(3): 161164.

63. Buchanan TA, Xiang AH (2005) Gestational diabetes mellitus. J Clin Invest 115(3): 485-491.

64. Xiong X, Buekens P, Fraser WD, Beck J, Offenbacher S (2006) Periodontal disease and adverse pregnancy outcomes: a systematic review. BJOG: An International Journal of Obstetrics \& Gynaecology 113(2): 135-143.

65. Kinane DF, Hart TC (2003) Genes and gene polymorphisms associated with periodontal disease. Critical Reviews in Oral Biology \& Medicine 14(6): 430-449.

66. Tsiavou A, Hatziagelaki E, Chaidaroglou A, Manginas A, Koniavitou K et al. (2004) TNF- $\alpha$, TGF- $\beta 1$, IL-10, IL-6, gene polymorphisms in Latent Autoimmune Diabetes of Adults (LADA) and type 2 diabetes mellitus. Journal of clinical immunology 24(6): 591-599.

67. Buchanan TA, Xiang AH (2005) Gestational diabetes mellitus. J Clin Invest 115(3): 485-491.

68. Mishra P, Gita B, Chandrasekaran SC (2014) Assessment of Periodontal Status in Association with Gestational Diabetes Mellitus: A CaseControlStudy. J Diabetes Metab 5: 467.

69. Zhou SY, Duan XQ Hu R (2013) Effect of nonsurgical periodontal therapy on serum levels of TNF- $\alpha$, IL- 6 and C-reactive protein in periodontitis subjects with stable coronary heart disease. Chin J Dent Res 16(2): 145-51.

70. Gonçalves TO, Costa D, Brodskyn CI, Duarte PM, Neto JBC, et al. (2010) Release of cytokines by stimulated peripheral blood mononuclear cells in chronic periodontitis. archives of oral biology 55(12): 975-980.

71. Endo Y, Tomofuji T, Ekuni D, Irie K, Azuma T, et al. (2010) Experimental periodontitis induces gene expression of proinflammatory cytokines in liver and white adipose tissues in obesity. Journal of periodontology 81(4): 520-526 
This work is licensed under Creative Commons Attribution 4.0 License DOI: 10.19080/ADOH.2018.09.555763

\section{Your next submission with Juniper Publishers} will reach you the below assets

- Quality Editorial service

- Swift Peer Review

- Reprints availability

- E-prints Service

- Manuscript Podcast for convenient understanding

- Global attainment for your research

- Manuscript accessibility in different formats

( Pdf, E-pub, Full Text, Audio)

- Unceasing customer service

Track the below URL for one-step submission https://juniperpublishers.com/online-submission.php 